${ }^{3}$ Klinika Angiologii, Nadciśnienia Tętniczego i Diabetologii

${ }^{4}$ Klinika Ortopedii i Traumatologii Narządu Ruchu

Uniwersytet Medyczny im. Piastów Śląskich we Wrocławiu

\title{
Active screening for diabetic foot assessment of health care professionals' compliance to it
}

\section{ABSTRACT}

Background. The strategy of care for chronic diabetic complications prevention includes appropriate organization and education of healthcare professionals. Despite the availability of skilled medical staff, there is insufficient information about the feet examination in standard practice. We evaluated the personnel's compliance in the context of following the guidelines for foot examination.

Materials and methods. We retrospectively analyzed 290 questionnaires from patients with diabetes mellitus (54.13\% women) enclosed in the medical records from Diabetic Foot Center.

Results. The mean patients' age was $63.24 ; 7.6 \%$ participants suffered from type 1 and $92.4 \%$ from type 2 diabetes; $17.6 \%$ patients declared previous foot examination: $31.8 \%$ with type $1,16.4 \%$ with type 2 diabetes and it was irrespective from: age, diabetes duration ( $p=0.6$ and $p=0.37$ respectively) and diabetes type ( $p=0.068)$.

Conclusion. The foot examination among patients with diabetes, by medical practitioners, is very poor. Neither patient age nor duration or type of diabetes had an influence on the decision for foot examination in our study. Our study has showed that not the guidelines

Address for correspondence:

dr hab. n. med. Edyta Sutkowska

Zakład Rehabilitacji, Klinika Ortopedii i Traumatologii Narządu Ruchu

Uniwersytet Medyczny im. Piastów Śląskich we Wrocławiu

e-mail: edytasutkowska@yahoo.com

Clinical Diabetology 2016, 5, 3, 83-87

DOI: $10.5603 /$ DK.2016.0014

Received: 12.04.2016 Accepted: 29.05.2016 but inadequate foot examination by medical staff could be the main problem of the prevention of diabetic foot. We should stress and re-educate patients but also medical staff about the foot examination. (Clin Diabet 2016; 5, 3: 83-87)

Key words: diabetic foot, foot examination, clinical practice, compliance, chronic complications

\section{Introduction}

Diabetic foot (DF) is one of the chronic diabetic complications. One in four patients with diabetes mellitus (DM) will develop DFU (diabetic foot ulcer) [1]. To avoid foot ulcerations patient education and regular feet examination should be performed [2]. It is estimated that even up to $85 \%$ of amputations due to DF can be reduced by identifying the at-risk foot and it proper prevention and/or treatment [2]. In case of a high-risk diabetic foot special procedures should be initiated to avoid amputation. Some high-risk patients need revascularization if ischaemia is present, or e.g. surgical correction if foot deformations are found.

The strategy of care for prevention includes, among others, appropriate organization and education of healthcare professionals [2]. The behavior of patients and the level of medical care have a significant impact on the cost of treating chronic diabetic complications and their prevalence. Understanding factors that influence on patient care provide important insights that will help in ameliorating the burden of diabetes. The level of medical care depends on the availability of qualified personnel and the ability to perform diagnostic and therapeutic procedures in accordance with current 
recommendations. Despite the availability of skilled medical staff, there is insufficient information about the feet examination in standard practice. To our knowledge, only a few studies have been devoted to medical staff compliance in the context of foot examination. De Bernardis with team evaluated how frequently patients had had their feet examination in the previous year and showed that more than $50 \%$ of the patients had not had them at all [3]. Also one study in Nigeria showed that $96.4 \%$ of symptomatic (neuropathy) and $97.3 \%$ of asymptomatic patients with DM had never had foot examination [4]. Al-Shafaee and co-authors assessed nine standards on the quality of diabetes care in primary care diabetic clinics in the north Al-Batinah region of Oman and found that only $39 \%$ of the patients had foot examination [5]. Information about quite good implementation of best practice guidelines recommendations comes from Australian podiatrists study [6] but authors mentioned that the character of the study limits its interpretation. The study was voluntary and podiatrists were aware about the aim so probably the majority of them, who decided to participate in this project more likely completed survey.

The aim of our study was to determine the compliance of practitioners in diabetic foot risk searching and detect factors (e.g. patient age, diabetes type and duration of the disease) which can mobilize them to examine the feet. The novelty of our study is that we asked patients, not practitioners, about previous foot examination, to reduce the bias of the study.

\section{Materials and methods}

In our retrospective study we analyzed 851 medical records of patients with diabetes mellitus who were consulted in the Diabetic Foot Center from October 2009 until the end of December 2010. This study was approved by local Medical University Commission of Bioethics (specific agreement number KB-434/2012).

\section{Characteristics of the Diabetic Foot Center and local guidelines}

The Center is mainly focused on patients' foot examination. Information about activities of the Center is available from October 2009 on posters, on the Center's website and is passed by physician who treat patients (general practitioners, diabetologists, endocrinologists) with DM. Patients are informed about the possibility of having their foot examination in the Center performed, despite the absence of diabetic foot signs or symptoms, provided they are residents. No medical referral is required to visit the Center. Visiting is not mandatory for the patients and depends only on their will.
Table 1. Questionnaire with information on previous foot examination

\begin{tabular}{lll}
\hline No & Question & Answer \\
\hline 1 & Initials \\
2 & Gender \\
3 & Age \\
4 & Duration of diabetes (years; if less \\
& than 1 year enter 0) \\
5 & Type 1 DM (yes: 1, no: 0) \\
6 & Type 2 DM (yes: 1, no: 0) \\
7 & Type 3 or 4 DM (yes: 1 and write the type, \\
& no: 0) \\
8 & Feet amputation (even partial) (yes: 1; no: 0) \\
9 & $\begin{array}{l}\text { Have your feet been ever examined } \\
\text { (yes: 1; no: } 0 \text { ): }\end{array}$ \\
& $\begin{array}{l}\text { pulse and/or sensory examination } \\
\text { (ask the nurse for details) }\end{array}$ \\
\hline
\end{tabular}

DM - diabetes mellitus

We did not analized how patients, who were examined in the Center, were informed about such a possibility.

According to local recommendations a foot examination should be performed in a patient with diabetes by a diabetologist, family doctor or an assistant nurse at least once a year. A typical foot examination consists of: pulse palpation and neurological examination (at least a monofilament and tuning fork test).

\section{Inclusion criteria}

We analyzed medical records of subjects with DM diagnosis with a known disease type (1 or 2) and duration who completed questionnaire with information on previous foot examination (Tab. 1). This questionnaire was previously prepared for internal purpose of the Center. The questionnaire was voluntary, and its fulfillment was proposed to each of 851 patients, who were examined during the above mentioned period.

\section{Acquisition of information}

The information was collected during visits by a skilled nurse, after having obtained the patient's oral consent. We excluded medical records without fully completed questionnaire.

\section{Assessed factors}

Based on the available information, we analyzed the impact of selected factors on the prevalence of foot examination: age, diabetes type and duration of the disease. According to the duration of the disease patients were assigned to one of the three groups: $0-5,6-9,>9$ years. 
Table 2. Characteristics of the studied population and foot examination according to diabetes type and duration

\begin{tabular}{lcc}
\hline Characteristic & $\begin{array}{c}\text { Total number of patients } \\
\mathbf{n}=\mathbf{2 9 0}(\%)\end{array}$ & $\begin{array}{c}\text { Number of patients with previous foot examination } \\
\mathbf{n}=\mathbf{5 1}(\%)\end{array}$ \\
\hline DM type 1 & $\mathrm{n}=22$ & $\mathrm{n}=7$ \\
& $(7.59)$ & $(31.82)$ \\
DM type 2 & $\mathrm{n}=268$ & $\mathrm{n}=44$ \\
& $(92.41)$ & $(16.42)$ \\
\hline DM duration & $\mathrm{n}=125$ & $\mathrm{n}=18$ \\
0-5 years & $(43.1)$ & $(14.4)$ \\
DM duration & $\mathrm{n}=43$ & $\mathrm{n}=10$ \\
6-9 years & $(14.83)$ & $(23.25)$ \\
DM duration & $\mathrm{n}=122$ & $\mathrm{n}=23$ \\
$>$ 9 years & $(42.07)$ & $(18.85)$ \\
\hline
\end{tabular}

DM - diabetes mellitus

\section{Statistics}

Statistical differences between mean values were determined using Student's t-test, and $\chi^{2}$ test for the assessment of the correlation between diabetes types or diabetes duration and the prevalence of the feet examination. A p value of less than 0.05 was considered statistically significant.

\section{Results}

We obtained complete data from 290 questionnaires: 157 (54.13\%) from women and 133 (45.86\%) from men. The mean age of the patients was 63.24 $(\mathrm{SD}= \pm 12.06)$ years.

This population seems to be representative for the population of the patients with DM, as we have found about $7.6 \%$ participants with type 1 and about $92.4 \%$ with type 2 diabetes - in general diabetic population it is $3-10 \%$ and $85-95 \%$, respectively.

The two dominating groups of patients among the participants were as follows: short ( $0-5$ years), $43.1 \%$; and long ( $>9$ years), $42 \%$ diabetes duration.

Only $17.59 \%$ patients have had foot examination done previously (minimum once from the DM diagnosis): $31.82 \%$ with DM type 1 and $16.42 \%$ patients with DM type 2 . The $p$ value for this assessment was not statistically significant (Tab. 2).

The mean age of the patients who have had foot examination performed was $62.4(S D= \pm 13.3)$ and for the group without previous foot examination was 63.4 (SD $= \pm 11.7$ ). We also analyzed foot examination by medical staff depending on the duration of DM - the results are shown in Table 2. Patient's age and diabetes duration did not influence decision regarding foot examination $(p=0.6$ and $p=0.37$ respectively).

\section{Discussion}

We observed a loss of awareness within the patients with DM in the mid-range (duration of DM, 6-9 years), perhaps as a result of patient self-confidence and/or a lack of any signs and symptoms of diabetic complications. People who suffer from chronic diseases, such as DM, believe that they can control their complications after achieving a stable course of the disease, for several years. Because chronic diabetic complications can be asymptomatic for many years in the initial phase, patients tend to forget about the risk of complications if adequate education is not available.

In addition to the lack of patient's awareness, medical staff care appears to be limited to providing a minimum attention without proper foot examination. The percentage of patients who declared that they have had one foot examination since being diagnosed with DM was approximately $18 \%$ in our assessment. Thus, the possibility of foot changes was taken into consideration in only one of five patients; the remainder number of patients did not have any control.

There are many studies on the compliance of patients, but testing medical staff compliance is not common. Meanwhile, even if information about proper foot hygiene is disseminated among patients, it does not protect them from the onset of diabetic foot. The education should always be accompanied by pulse and neuropathy testing - which are easily detected and crucial for the initiation of preventive strategies [2]. Also calluses or foot deformities, without neuropathy, are associated with a high risk of ulcerations [7].

Our data are alarming in the face of findings from the other part of the study. The level of education among 291 patients with DM living in our city (population more than 630,000 ) was also inadequate - only 
$13.1 \%$ participants presented sufficient knowledge about diabetic foot risk factors and self-protection principles [8].

We expect that patients with active or past ulcers are under the care of surgeons, but other patients with DM, for whom primary DF prophylaxis plays a crucial role, are unaware of the risks. Furthermore, their doctors seem unaware of the risks associated with DM, due to the lack of knowledge of the results of foot examination, as has been shown in this paper. This situation affects patients mainly with type $2 \mathrm{DM}$, who constitute a greater portion of the diabetic population, only $16.4 \%$ of such patients had foot examination. Among participants with type $1 \mathrm{DM}$ approximately $32 \%$ had foot examination. To search for the basis for such a situation, we can only suggest that patients with type $1 \mathrm{DM}$ are treated by specialists and there is an active search for chronic diabetic complications, whereas patients with type 2 DM are most often under the care of family physicians.

Neither age of the patient nor duration of DM had an influence on the decision for foot examination in our retrospective study $(p=0.67$ and $p=0.37$, respectively).

It seems that the best practice guidelines, even if developed, are not being put into practice. Meanwhile, the prevalence and costs of DFU treatment are still growing [9]. As was shown in one study [10] we can partially improve such situation (proper care) through monitoring. At this study the prevalence of foot examination rose from $22.4 \%$ to $64.1 \%$ because of clinical audit.

There is an urgent need for medical staff to prevent DF complications. Some countries have introduced special, national programs to improve diabetes care to avoid or minimize the risk of amputations. An example of this strategy could be a proper podiatric medical care. This specialist care can reduce the work of doctors and nurses. One study showed that podiatric medical care can reduce the economic burdens of diabetes associated with foot complications [11].

The limitations of our study are mainly related to its retrospective nature and the nature of the Center. This means the absence of data on potential confounding factors, such as the level of experience of the basic healthcare personnel, the impact of the presence of other chronic complications or $\mathrm{HbA}_{1 \mathrm{c}}$ value, all of which may influence the personnel's decision whether or not to examine the patient. However, regardless of experience or skills, pulse evaluation and basic foot neurological examination should be performed at least once a year. If the results are not clear, the patient should be referred to a specialist center. Our data seem to be representative of the entire diabetic population because even if we involved patients from one center, they came from different medical practices of a large urban area.

\section{Conclusions}

The health care professionals' compliance in screening for diabetic foot is low. The recommendations are only the first step towards good healthcare. We often forget that they are not designed for patients but mostly for the health care professionals. Our study has shown that despite the guidelines on the prevention of diabetic foot, the problem that remains is inadequate foot examination by medical staff. We should stress and re-educate medical practitioners about chronic foot complications and encourage them to regular foot examination. The time we devote to examine our patients is reduced due to the constant increase in the number of patients with DM. Increasing the number of medical staff for diabetic care and the inclusion of special care cards for medical records, can help to improve medical staff compliance. This requires further analysis and confirmation of effectiveness.

\section{Conflict of interest}

ES was working as diabetologist at Diabetic Foot Center (October 2009-February 2011). The authors declare that there is no duality of interest associated with this manuscript.

\section{Acknowledgements}

We thank DrMS, director of the Diabetic Foot Center, who agreed to performe our study in this center. We thank Nurse EP for surveying the patients.

\section{REFERENCES}

1. Singh N, Armstrong DG, Lipsky BA. Preventing foot ulcers in patients with diabetes. JAMA 2005; 293: 217-228.

2. Bakker K, Apelqvist J, Lipsky BA, Van Netten JJ; International Working Group on the Diabetic Foot (IWGDF). The 2015 IWGDF guidance documents on prevention and management of foot problems in diabetes: development of an evidence-based global consensus. Diabetes Metab Res Rev 2016; 32 (suppl 1): 2-6.

3. De Berardis G, Pellegrini F, Franciosi M et al. QuED Study Group-Quality of Care and Outcomes in type 2 Diabetes. Are type 2 diabetic patients offered adequate foot care? The role of physician and patient characteristics. J Diabetes Complications 2005; 19: 319-327.

4. Oguejiofor OC, Oli JM, Odenigbo CU. Evaluation of "care of the foot" as risk factor for diabetic foot ulceration: the role of internal physicians. Niger J Clin Pract 2009; 12: 42-46.

5. Al-Shafaee M, Al-Farsi Y, Al-Kaabi Y et al. Quality of diabetes care in primary health centres in North Al-Batinah of Oman. Open Cardiovasc Med J 2014; 8: 48-54.

6. Quinton TR, Lazzarini P, Boyle FM et al. How do Australian podiatrists manage patients with diabetes? The Australian diabetic foot management survey. J Foot Ankle Res 2015; 8: 16.

7. Lazaro-Martinez JL, Aragon-Sanchez FJ, Beneit-Montesinos JV et al. Foot biomechanics in patients with diabetes mellitus: doubts 
regarding the relationship between neuropathy, foot motion, and deformities. J Am Podiatr Med Assoc 2011; 101: 208-214.

8. Sutkowska E. Diabetic foot prevention among the patients with diabetes living in Wroclaw based on their education assessment. Diabet Klin 2012; 1: 46-151.

9. Cavanagh $P$, Attinger $C$, Abbas $Z$ et al. Cost of treating diabetic foot ulcers in five different countries. Diabets Metab Res Rev 2012; 28 (suppl 1): 107-111.
10. Tan F, Liew SF, Chan $G$ et al. Improving diabetes care in a public hospital medical clinic: report of a completed audit cycle. J Eval Clin Pract 2011; 17: 40-44.

11. Carls GS, Gibson TB, Driver VR et al. The economic value of specialized lower-extremity medical care by podiatric physicians in the treatment of diabetic foot ulcers. J Am Podiatr Med Assoc 2011; 101: 93-115. 